
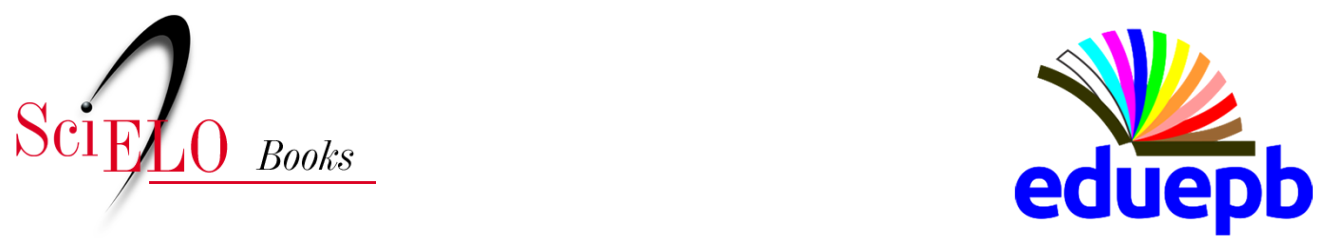

Aprendendo e fazendo com o Mestre

\title{
Carlos Miranda - Não dá para imaginar um Nordeste (e o Brasil) sem Celso Furtado
}

\author{
Milena Barros Marques dos Santos \\ Cidoval Morais de Sousa
}

\section{SciELO Books / SciELO Livros / SciELO Libros}

SANTOS, M. B. M., and SOUSA, C. M. Carlos Miranda - Não dá para imaginar um Nordeste (e o Brasil) sem Celso Furtado. Interviewed: Carlos Miranda. In: SOUSA, C. M., THEIS, I. M., and BARBOSA, J. L. A., eds. Celso Furtado: a esperança militante (Depoimentos): vol. 2 [online]. Campina Grande: EDUEPB, 2020, pp. 168-175. Projeto editorial 100 anos de Celso Furtado collection. ISBN: 978-65-86221-11-4. https://doi.org/10.7476/9786586221671.0006.

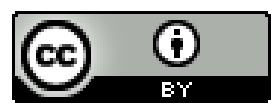

All the contents of this work, except where otherwise noted, is licensed under a Creative Commons Attribution 4.0 International license.

Todo o conteúdo deste trabalho, exceto quando houver ressalva, é publicado sob a licença Creative Commons Atribição 4.0.

Todo el contenido de esta obra, excepto donde se indique lo contrario, está bajo licencia de la licencia Creative Commons Reconocimento 4.0. 


\section{Carlos Miranda}
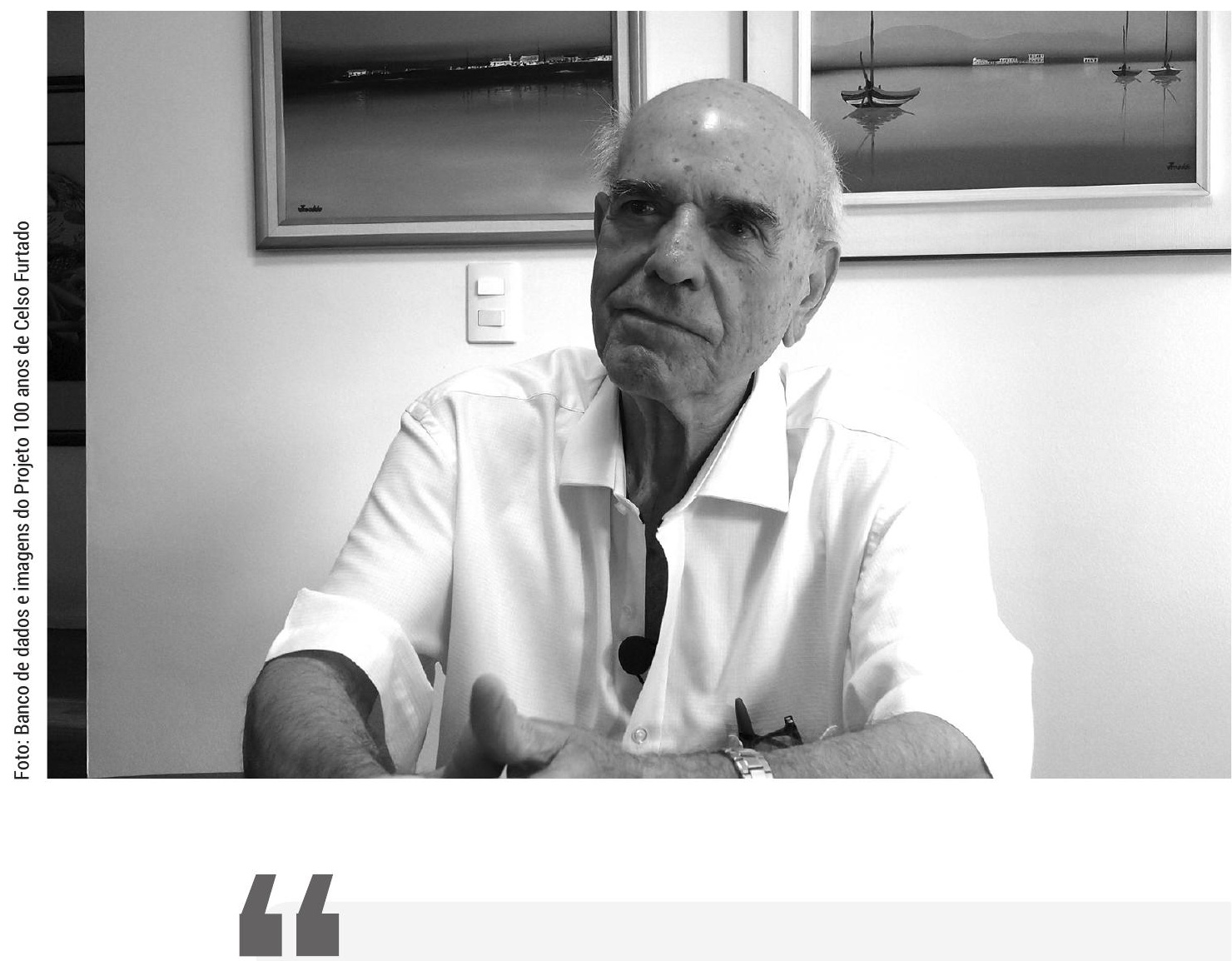

Uma coisa importante para mim foi compreender a importância do território como identidade política das pessoas. As pessoas se identificam com o lugar. Elas são mais 0 lugar onde vivem do que qualquer outra coisa. Celso partiu desse sentimento de pertencer, que leva a uma série de desdobramentos, que eu acho que é fundamental. $E$ aprendi o que é pertencer quando entrei na Sudene. 


\title{
Não dá para imaginar um Nordeste (e o Brasil) sem Celso Furtado
}

\author{
Milena Barros Marques dos Santos1 \\ Cidoval Morais de Sousaz
}

\begin{abstract}
Carlos Luiz de Miranda ${ }^{3}$ foi um aluno dedicado. Ele se entusiasma ao relembrar a excelente nota alcançada aos 23 anos, em 1961, em Desenvolvimento Econômico, disciplina da primeira turma do curso Técnico em Desenvolvimento Econômico (TDE) da Sudene $e^{4}$. Os conteúdos foram ministrados pelo criador e então superintendente da instituição, um dos mais destacados intelectuais do século XX, o paraibano Celso Monteiro Furtado (1920 - 2004). Mas, os ensinamentos do grande pensador não se limitaram à sala de aula; era, também, possível aprender com suas atitudes cotidianas.
\end{abstract}

Certa vez, recorda Miranda, o elevador do edifício em que funcionava a Sudene em Recife quebrou. O prédio era alto. Furtado chegara com sua pasta carregada de livros e documentos e, não teve dúvidas,

1 Jornalista, Mestranda em Desenvolvimento Regional (PPGDR UEPB), Especialista em Gestão Pública, documentarista.

2 Jornalista, Doutor em Geociências pela Unicamp, professor e pesquisador da Universidade Estadual da Paraíba (UEPB), vinculado aos Programas de Pósgraduação em Desenvolvimento Regional e Ensino de Ciências e Educação Matemática. Colabora com o PPGCTS da UFSCar.

3 Bacharel em Ciências Jurídicas e Sociais (UFPE); especialista em Formulação, Execução e Gestão de Políticas Públicas de Desenvolvimento Rural Sustentável. Trabalhou na Sudene de 1961 a 1972 como especialista em Desenvolvimento Rural, tendo coordenado o Grupo de Análise e Planejamento Agrícola (GAPA). Criador e diretor executivo da Companhia de Ação e Desenvolvimento Regional (19721987). Trabalhou no Instituto Interamericano de Cooperação para Agricultura (IICA). Organizou 12 Fóruns Internacionais anuais sobre Desenvolvimento Rural Sustentável. Implementou cursos de formação de gestores públicos, técnicos, dirigentes e lideranças. Organizador da Série de Desenvolvimento Rural e Sustentável que possui 24 volumes.

4 Curso oferecido pela Sudene à maioria de seus técnicos, para que pudessem dispor de mesma linguagem sobre o desenvolvimento. Os técnicos eram profissionais de diversas formações como agrônomos, advogados, engenheiros, arquitetos e médicos. 
subiu a escadaria e foi trabalhar. A lição aprendida foi de que obstáculos devem ser superados, e um importante traço da personalidade de Furtado se evidenciava em ações corriqueiras: transpor desafios. O aprendizado marcou a vida do pernambucano de Canhotinho, hoje com 82 anos, bacharel em Ciências Jurídicas e Sociais pela Universidade Federal de Pernambuco.

À época, início dos anos 1960, um dos desafios da Sudene se relacionava, também, com uma compreensão de desenvolvimento. Furtado, então, proporcionou à equipe formação em bases teórica e prática. Não se tratava de "formar qualquer pessoa, mas indivíduos com sentimento de pertença a uma causa, que se identificassem com os propósitos do desenvolvimento". E foi assim que, segundo Miranda, se tornou possível, em setores como o Departamento de Agricultura e Abastecimento da Sudene, unir questões operacionais, práticas e pragmáticas, sem se descuidar das questões políticas e teóricas. A instituição reconheceu a diversidade da região e valorizou a identidade dos territórios. Não havia receita pronta e nem única. Cada realidade exigia uma construção específica.

Esses conhecimentos, décadas depois, foram consolidados em sua experiência profissional no IICA (Instituto Interamericano de Cooperação para Agricultura), em diversos países da América Latina, onde trabalhou, principalmente, com políticas públicas de desenvolvimento agrário com enfoque territorial. Para o pernambucano, o pensamento de Furtado foi relevante em sua trajetória de vida e destaca como maior contribuição os ensinamentos relacionados a políticas públicas de desenvolvimento regional. "Imagine o Nordeste sem Furtado!? Seria um vazio essa história toda”. Confira, a seguir, essas e outras questões tratadas por Carlos Miranda à luz das comemorações do centenário de Furtado, em entrevista concedida em fevereiro de 2020, em Brasília, onde atualmente reside.

\section{Entrevista}

- Como o senhor começou na Sudene? O senhor fez o curso de Técnico em Desenvolvimento? Foi aluno de Furtado?

Eu sou bacharel em Ciências Jurídicas e Sociais pela Universidade Federal de Pernambuco e comecei com desenvolvimento rural na Sudene. Mais do que isso: políticas de desenvolvimento. Foi a isso que sempre demos ênfase em nosso trabalho. E uma das coisas que 
tenho como marca na minha vida é ter sido aluno de Celso Furtado. Eu nunca me esqueço de uma coisa: na prova que eu fiz, concluindo a disciplina que ele dava, eu tirei 9. Numa escala de o a 10.

- Então, o senhor estava muito bem. A disciplina, o senhor lembra qual era, do que tratava?

Era Desenvolvimento Econômico. Ele falava de tudo, né? Na verdade,

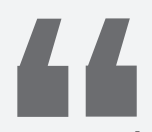

Eu acho que um dos grandes trabalhos que se fez foi criar 0 Departamento de Agricultura e Abastecimento da Sudene. Ali, a gente conseguia unir questões operacionais, práticas e pragmáticas sem se desligar das questões políticas e teóricas do desenvolvimento.

o que a gente descobriu foi que estava diante de uma estratégia de desenvolvimento regional, de uma política de desenvolvimento regional. Eu não sei se houve uma turma anterior à minha. Mas eu entrei na Sudene bem no começo, era um negócio pequeno ainda, porque veio, primeiro, a Openo ${ }^{5}$. Não tinha nem plano diretor ainda. O texto básico era "Operação Nordeste". Era o que estava em voga. E na realidade o que era Openo? Era uma estratégia de desenvolvimento regional. E que deu certo! Deu certo enquanto durou.

\section{- O seu primeiro momento da Sudene foi para trabalhar como} ....

Especialista em Desenvolvimento Rural. A gente trabalhava o que aprendia no curso de TDE.

- O senhor se lembra de quais eram os desafios daquele momento?

Era ter uma base teórica e prática em matéria de desenvolvimento. Eu acho que um dos grandes trabalhos que se fez foi criar o Departamento de Agricultura e Abastecimento da Sudene. Ali a gente conseguia unir questões operacionais, práticas e pragmáticas sem se desligar das questões políticas e teóricas do desenvolvimento.

5 Conjunto de políticas para o desenvolvimento do Nordeste apresentado pelo economista Celso Furtado em palestra denominada de "A Operação Nordeste", ocorrida no ISEB, em 1959, e que tinha como propósito conquistar apoio para os estudos desenvolvidos no âmbito do Grupo de Trabalho para o Desenvolvimento do Nordeste (GTDN), durante o governo de Juscelino Kubitscheck. 
- Do ponto de vista político e estratégico como o senhor diferencia a Sudene do DNOCS?

A diferença está pelo ponto de vista das políticas de desenvolvimento. Eu acho que o DNOCS não conseguiu levar à prática as políticas de desenvolvimento que a região precisava. Por exemplo, no Nordeste se pensava em Mata, Agreste e Sertão. A Sudene mostrava que o Nordeste era muito mais do que isso.

- Qual foi o Nordeste pensado pela Sudene no tempo de Furtado? Eu diria, [um Nordeste] mais multifacetado, mais diversificado. A Sudene olhou muito para essa diversidade. Os meus primeiros exercícios com a diversidade foram feitos na Sudene. Eu tive dez anos de Sudene, e isso me deu uma formação muito importante, sobretudo em matéria de políticas de desenvolvimento. $\mathrm{O}$ grande legado da Sudene foi esse aí, trabalhar políticas de desenvolvimento.

- Neste seu tempo, o que o senhor pode nos contar sobre o homem Furtado?

Eu fui aluno de Celso Furtado. Minha convivência com ele foi mais intelectual do que física. Foi de muita formação que eu recebi. Eu fui me construindo com ele.

- Tem alguma característica da pessoa dele que o senhor destaca? Deixe eu contar um causo, já que Otamar gosta de contar causos (risos). Eu aprendi uma coisa interessante. A Sudene tinha se mudado para um edifício ali na Dantas Barreto [Recife]... Uma vez Celso Furtado chegou, e você veja como são as coisas, o elevador estava quebrado. Ele não teve dúvidas - ele andava com uma pasta carregada de livros e documentos - enfrentou a escadaria. Eu não sei que andar era, mas sei que era nos últimos andares. E era muita escada. Então aí a gente vai aprendendo uma coisa, né? Os obstáculos são para a gente ultrapassar.

- Tem outras lembranças que o senhor gostaria de compartilhar de Furtado? Algo marcante...

A característica principal era que sempre que ele se sentia desafiado agia para superar esses desafios. Para mim isso foi uma coisa que me marcou muito. Por exemplo, essa coisa que eu estou falando de ele subir a pé a escadaria mostra que muita coisa a gente pode fazer. Veja 
o momento atual que a gente vive no Brasil. Isso, se você não tiver força para superar, saber que é um momento numa trajetória, você sucumbe.

- O senhor viveu a Sudene com Celso e a Sudene sem Celso Furtado. O senhor poderia falar um pouco sobre esses dois tempos?

Eu fiquei [na Sudene] até 1971. Em 1971, eu fui para a Bahia. O interessante dessa ida a Bahia é que eu fui dirigir um projeto de desenvolvimento regional no Recôncavo Baiano. E o regional ensina muito a importância da diversidade. Depois, trabalhando fora do Brasil, é que eu me dei conta da diversidade. A diversidade é uma riqueza! Ninguém é condenado por ser diverso. Então, vivendo em vários países, é que eu consolidei o que eu tinha aprendido na Sudene de Celso: a importância da diversidade. Não tinha receita pronta; você tinha que construir mesmo. Cada momento era um momento de construção. Otamar fala, em seu livro, de um Grupo de Planejamento e Ação Regional, o GAPA. E recordou o que era o GAPA. Eu tive a sorte de ser responsável pelo GAPA. Foi um momento de riqueza muito grande. Aprendi, com o GAPA, que as políticas não podem ser iguais para todos.

- O senhor disse que depois veio a compreender melhor essa coisa da diversidade quando esteve fora...

Antes do período fora do Brasil, tive um período muito importante para mim, na Bahia, durante sete anos. Lá, a gente teve a oportunidade de criar uma empresa de desenvolvimento regional. E o que a gente fez? Primeiro, a importância da formação de pessoas, que aprendemos, todos, com Celso. Mas não de qualquer pessoa, mas de pessoas identificadas com os propósitos do desenvolvimento. Uma coisa que a gente sempre tratou durante esses sete anos foi que é mais importante você ter uma causa, ter pertença, ser ligado a esse processo, do que qualquer outra coisa. Para mim isso se consolidou na vivência internacional. É um outro ângulo de você ver as coisas, né?

- Nesta experiência internacional Celso também, de algum modo, esteve na sua vida?

Ele me acompanhou a vida toda, porque os livros, enfim... Por que é que eu fui para fora do Brasil? Fui trabalhar num negócio chamado IICA - Instituto Interamericano de Cooperação para a Agricultura. 
Eu nunca imaginei que iria para o IICA. Eu optei pelo IICA, porque isso me dava a oportunidade de usar uma coisa que eu aprendi na Sudene, que foi a liberdade de trabalho. Temas, assuntos, tudo isso. Eu aprendi dessa forma. Mais do que isso. Eu exercitei dessa forma. Quando eu voltei para o IICA aqui [no Brasil], o meu trabalho foi nos estados do Nordeste. Eu nunca me afastei. O foco sempre foi esse. Eu voltei para a Bahia, trabalhei na Paraíba, trabalhei no Rio Grande do Norte, trabalhei no Maranhão. E mais, aprendi uma coisa, que eu devo à formação original, inicial, de Celso Furtado, que foi a importância da formação, que não é só de organizar pensamento, mas é formar pessoas mesmo. Quando eu falo formar, falo nisso aí. Nessa vertente. Não é só algo acadêmico. É um projeto de vida. Aprendi isso. E as coisas que fiz fora do Brasil foram em cima disso. Eu trabalhei muito em toda a América Latina. Foi praticamente em todos os países. Inclusive no Haiti, imagina.

- Em todos eles trabalhando com políticas de desenvolvimento? Sim, trabalhando com políticas públicas de desenvolvimento agrário, com um enfoque territorial. Porque umas das coisas importantes para mim foi compreender a importância do território como identidade política das pessoas. As pessoas se identificam com o lugar. As pessoas são mais o lugar onde elas vivem do que qualquer outra coisa. A gente começou a trabalhar com essa questão do território e era a continuação de um trabalho que começamos na Sudene, nada diferente. Claro que você vai evoluindo, e o seu pensamento vai evoluindo, enfim. Mas essa vivência, mais de caráter internacional, foi para redescobrir as identidades, que têm a ver com o lado cultural. Então, quando eu regressei ao Brasil, voltei com o firme propósito de trabalhar a questão das identidades associadas aos lugares de origem das pessoas. Aos espaços que as pessoas ocupavam nos lugares. Por isso foi muito fácil compreender o Maranhão.

\section{- Por essa perspectiva...}

Compreender, por exemplo, o vizinho, o Piauí. Você encontra um camarada que diz que é primeiro brasileiro, depois ele diz o lugar de onde ele veio, o território de onde ele veio. Aí ele vai numa escala ...

- "Eu sou lá do sítio mesmo!" (risos)

Exatamente. Ele vai nessa escala e chega no lugar e diz "eu sou daqui”. 
- "Sou lá de Cajazeiras, de São José dos Espinharas".

Ser de Cajazeiras é uma identidade. Não é a do geógrafo. Outra coisa interessante, eu acho que o primeiro trabalho de regionalização do Nordeste a gente fez com, não sei se você conhece, Manuel Correia de Andrade. Quando éramos do GAPA, em busca dessa identidade, nós fizemos uma regionalização, acho que foi primeira vez na Sudene, e tratamos de aprofundar o conceito de "regional" associado aos lugares e ao pertencimento das pessoas.

\section{- Isso nos anos 1960 ainda?}

Anos 6o, com Manuel Correia de Andrade. O que a gente fez foi uma regionalização do Nordeste. Mas o trabalho de identidade veio por outra vertente. Para mim já veio mais quando eu regressei ao Brasil. Aí eu comecei a trabalhar com identidade. Veja uma coisa interessante. No fundo, a Sudesul não deu certo porque não tinha identidade. $\mathrm{O}$ Sul é o Sul.

\section{- Para o senhor, qual a maior contribuição de Furtado?}

Nessa trajetória toda, eu comecei a perceber que, muito mais do que as técnicas do planejamento - e as técnicas são fundamentais - teve a contribuição que Celso deu ao desenvolvimento das políticas, etc. Mas ele partiu desse sentimento de pertencer, que leva a uma série de desdobramentos, que eu acho que é fundamental. Porque eu aprendi o que é pertencer quando entrei na Sudene. Até hoje eu sou de Pernambuco, do agreste pernambucano.

\section{- De que padece o desenvolvimento rural hoje? De que padecem as políticas de desenvolvimento?}

Eu acho que o território continua a ser o elemento central, pelo menos para a discussão de política. Eu acho que fora do território o problema é você chegar a uma identidade territorial. Uma vez chegada à identidade territorial - porque eu trabalhei muito com isso, eu não consigo me desligar - uma coisa que aprendi na Sudene, foi que ela [a identidade territorial] pauta a vida da pessoa. 
- Para o senhor, o que não funcionou na Sudene de seu tempo teve a ver com a falta de institucionalidade...?

A Sudene se viu compelida a criar 23 empresas de economia mista porque era possível, com essas empresas, chegar aos territórios. Outro dia eu estava falando sobre isso. Qual foi a razão de a Sudene chegar a 23 empresas de economia mista? Na época, o que é hoje empresa pública, era de economia mista. Era um tipo de economia que mesclava a importância do governo com o Estado. O que levou a isso? Foi a forma que encontraram de trabalhar território.

- Qual é a leitura que o senhor faz das políticas públicas hoje? Eu acho que não tem. Você encontra ainda em alguns estados, mas são manifestações... acabou mesmo. Se você me perguntar se é possível recuperar, eu digo que é, mas não vejo [como].

- O governo Lula-Dilma, de certa forma, resgatou o ideal desenvolvimentista?

Não. Foi outra forma de abordagem. Embora eu reconheça todos os avanços, tudo isso aí, acho que não. Pelo menos a eleição de Dilma se deveu a isso, aos avanços. Eu tinha muita esperança e perdi.

\section{- O senhor acha que estamos no labirinto?}

Eu não sei. Eu não sei se é um labirinto. Falar de labirinto talvez não seja o mais adequado. Mas muita gente acha que é um labirinto. Mas eu não sei se é...

- No seu ponto de vista, a gente ainda pode fazer alguma coisa? Eu acho que sim. Embora com todas essas dificuldades, com esses percalços todos, não devemos perder as oportunidades. Isso faz a gente ter uma responsabilidade, que é buscar esses passos, essas possibilidades, essas alternativas.

- Que mensagem o senhor deixa? Olhando para o seu legado... Olhando para o meu legado, eu simplesmente diria o seguinte: não seria possível a existência sem o legado de Celso Furtado, pensando no desenvolvimento, sobretudo. Imagine o Nordeste sem Furtado. Seria um vazio essa história toda. 